\title{
Effect of Lepidium meyenii (Maca), a root with aphrodisiac and fertility-enhancing properties, on serum reproductive hormone levels in adult healthy men
}

\author{
G F Gonzales, A Córdova, K Vega, A Chung, A Villena \\ and C Góñez
}

Instituto de Investigaciones de la Altura, and Department of Biological and Physiological Sciences (Faculty of Sciences and Philosophy), Universidad Peruana Cayetano Heredia, PO 1843, Lima, Peru

(Requests for offprints should be addressed to G F Gonzales; Email: iiad@upch.edu.pe)

\begin{abstract}
Lepidium meyenii (Maca) is a Peruvian hypocotyl that grows exclusively between 4000 and $4500 \mathrm{~m}$ in the central Andes. Maca is traditionally employed in the Andean region for its supposed aphrodisiac and/or fertilityenhancing properties.

This study was a 12-week double-blind, placebocontrolled, randomized, parallel trial in which active treatment with different doses of Maca Gelatinizada was compared with a placebo. The study aimed to test the hypothesis that Maca has no effect on serum reproductive hormone levels in apparently healthy men when administered in doses used for aphrodisiac and/or fertilityenhancing properties. Men aged between 21 and 56 years received $1500 \mathrm{mg}$ or $3000 \mathrm{mg}$ Maca.
\end{abstract}

Serum levels of luteinizing hormone, folliclestimulating hormone, prolactin, 17-alpha hydroxyprogesterone, testosterone and 17-beta estradiol were measured before and at 2, 4, 8 and 12 weeks of treatment with placebo or Maca ( $1.5 \mathrm{~g}$ or $3.0 \mathrm{~g}$ per day). Data showed that compared with placebo Maca had no effect on any of the hormones studied nor did the hormones show any changes over time. Multiple regression analysis showed that serum testosterone levels were not affected by treatment with Maca at any of the times studied ( $P$, not significant).

In conclusion, treatment with Maca does not affect serum reproductive hormone levels.

Journal of Endocrinology (2003) 176, 163-168

\section{Introduction}

Sexual function is an important component of quality of life and subjective well being in humans. Sexual problems are widespread and adversely affect mood, well being, and interpersonal functioning (Laumann et al. 1999). The main sexual problems are related to sexual desire and male erectile dysfunction. Successful treatment of sexual dysfunction may improve not only sexual relationships, but also the overall quality of life. Alternatives for treatment of hypoactive sexual desire are scarce. Testosterone is used because of its ability to stimulate sexual desire in hypogonadal men (Matsumoto 1994, Arver et al. 1996). Other compounds are potent regulators of sexual behavior in animals but not in healthy men (Perras et al. 2001).

Despite the fact that testosterone may be used for hypoactive sexual desire (Seidman 2000), many people in the world prefer to use natural plants. One example is the broad use of ginseng due to its supposed aphrodisiacenhancing property (Kim et al. 1976).

The aphrodisiac properties of the root of Lepidium meyenii (Maca) have recently been described (Zheng et al.
2000, Cicero et al. 2001, 2002). Additionally, a favorable effect on spermatogenesis has been observed in both adult male rats (Gonzales et al. 2001a) and adult men (Gonzales et al. 2001b). Maca (Lepidium meyenii) is a Peruvian hypocotyl which belongs to the Brassicaceae family and grows exclusively between 4000 and $4500 \mathrm{~m}$ above sea level in the central Peruvian Andes. For centuries, its properties of improving sexuality and fertility have been recognized (see Obregon 1998). The activity of the plant is located in the root. Maca is a commercially available product marketed as a nutrient in different forms including tablets obtainable in drugstores. Studies in rodents suggest that Maca may improve sexual behavior (Zheng et al. 2000, Cicero et al. 2001, 2002). An effect of Maca on sexual desire has also been described in normal men treated with 1.5 or $3.0 \mathrm{~g}$ Maca per day during 12 weeks in a randomized double-blind trial (Córdova et al. 2001). In this study the effect of Maca was compared with the effect of a placebo at 4,8 and 12 weeks of treatment. An increase in sexual desire was noticeable in apparently healthy men taking Maca at 8 and 12 weeks of treatment. 
Sexual desire may be elicited by testosterone (Haren et al. 2002); however, there is no evidence that the improvement in sexual desire elicited by Maca (Córdova et al. 2001) was due to an increase in serum testosterone levels or a testosterone-like effect.

For this reason, the present study was designed to determine if Maca administered to healthy men, in doses commonly used in Peru as a sexual stimulant, energizer and nutrient, affects the serum levels of testosterone, its precursor, 17-alpha hydroxyprogesterone (17-OHP), and its metabolite, 17-beta estradiol. This kind of study is important since testosterone may be a promoter of prostate cancer (Nelson \& Witte 2002). Such undesirable effects may limit the use of any compound which induces an increase in serum testosterone levels in healthy men. The present study also aimed to determine the effect of Maca on serum levels of luteinizing hormone (LH), follicle-stimulating hormone (FSH), and prolactin (PRL) in adult healthy men.

\section{Materials and Methods}

\section{Design}

The study was a 12-week, double-blind, placebocontrolled, randomized, parallel trial in which active treatment with Maca Gelatinizada was compared with placebo. The study aimed to demonstrate an effect of Maca on serum reproductive hormone levels.

The study was performed during the summer between December 2000 and March 2001. The Institutional Review Board of the Scientific Research Office from the Universidad Peruana Cayetano Heredia approved the study.

\section{Subjects}

Fifty-six subjects, aged 21 to 56 years, were included in the study. All subjects were in apparently good health. Men were randomly placed in one of six groups. Three groups received active treatment whereas the other three groups received placebo. For 12 weeks, one group $(n=15)$ received three tablets a day $(1.5 \mathrm{~g})$ of gelatinized Maca (Maca Gelatinizada La Molina, Lima), in a dose of one tablet each $8 \mathrm{~h}$ (Maca 1). Men of the second group $(n=15)$ received six tablets a day of gelatinized Maca $(3 \cdot 0 \mathrm{~g})$, in a dose of two tablets every $8 \mathrm{~h}$ (Maca 2). The third group $(n=15)$ received three tablets a day of gelatinized Maca in the morning ( $1.5 \mathrm{~g}$ ) (Maca 3). The other three groups received tablets of placebo daily for the 12-week study span in the same schedule as the Maca groups. The placebo group included 12 men. Of these, four received 6 tablets a day and eight received 3 tablets a day. During the study, all men maintained their usual eating regimen. One man in the second group (Maca 2) was receiving medical treatment at the time of the study. Data from this subject was not included.
Men included in the study, except the subject excluded from Maca 2, did not use drugs for at least 3 months before the study, nor did they use dietary supplements. Thirtyone men did not smoke, seventeen smoked less than 4 cigarettes a week, eight men smoked between 5 and 15 cigarettes a week, and one subject smoked 2 packets of cigarettes a week. This last subject had normal basal serum reproductive hormone levels.

Laboratorios Hersil (Lima, Peru) provided the tablets of gelatinized Maca (Maca Gelatinizada La Molina). Each tablet contains $500 \mathrm{mg}$ dehydrated root of Maca (Lepidium meyenii).

Venous blood samples were drawn after a 12 -h overnight fast before treatment and at 2, 4, 8 and 12 weeks of treatment with Maca or placebo. Blood was centrifuged at 3000 r.p.m., and serum was collected after centrifugation and kept frozen until assayed for hormone measurements.

\section{Hormone measurements}

Serum 17-OHP, testosterone and estradiol concentrations were determined by radioimmunoassay (RIA) using ${ }^{125} \mathrm{I}-$ labeled 17-OHP, ${ }^{125}$ I-labeled testosterone and ${ }^{125} \mathrm{I}-$ labeled estradiol, respectively, as radioactive markers. The assays were performed using commercially available kits (Diagnostic Products Co., Los Angeles, CA, USA). All samples were run in the same assay period. The withinassay variation was $5 \cdot 6 \%$ for hydroxyprogesterone, $5 \cdot 5 \%$ for testosterone and $6.4 \%$ for estradiol. The sensitivities of the hydroxyprogesterone, testosterone and estradiol assays were $0.07 \mathrm{ng} / \mathrm{ml}, 4.0 \mathrm{pg} / \mathrm{ml}$ and $8 \mathrm{pg} / \mathrm{ml}$ respectively.

Serum FSH, LH and PRL levels were measured by immunoradiometric assay (IRMA) in solid phase using commercially available kits (Diagnostic Products Co.). Within-assay variation was $2.9 \%$ for $\mathrm{FSH}, 1.3 \%$ for $\mathrm{LH}$, and $1.8 \%$ for PRL. The sensitivities of the assays were $0.06 \mathrm{mIU} / \mathrm{ml}$ for $\mathrm{FSH}, 0.15 \mathrm{mIU} / \mathrm{ml}$ for $\mathrm{LH}$, and $0 \cdot 1 \mathrm{ng} / \mathrm{ml}$ for PRL.

$\mathrm{LH}$ results are expressed as $\mathrm{mIU} / \mathrm{ml}$ in terms of the World Health Organization's First International Reference Preparation of LH for immunoassay, number 68/40 (1st IRP 68/40) and WHO's Second International Reference preparation of LH for immunoassay, number 80/552 (2nd IRP 80/552). FSH results are expressed as $\mathrm{mIU} / \mathrm{ml}$ in terms of WHO's Second International Reference Preparation of Pituitary FSH, number 78/549 (2nd IRP 78/549). Prolactin results are expressed as $\mathrm{ng} / \mathrm{ml}$ in terms of the WHO's Third International Standard for prolactin, number $84 / 500$. To convert $\mathrm{ng} / \mathrm{ml}$ to $\mathrm{mIU} / 1$, data should be multiplied by $21 \cdot 2$.

\section{Statistical analysis}

Data were analyzed using the statistical package STATA (version 7·0) for the personal computer (Stata Corporation, 702 University Drive East, College Station, TX, USA). 
Data are presented as means \pm standard error of the mean (S.E.M.). Differences between treatments and differences over time were assessed by two-way analysis of variance. Data of serum hormones were also transformed to logarithm and submitted to a two-way analysis of variance. A multiple regression analysis was also performed to determine the independent effect of treatment, time of treatment, and serum hydroxyprogesterone and estradiol levels on serum testosterone levels (dependent variable). Treatment was assessed as a dummy variable comparing data with respect to values in the placebo group. Time was assessed also as a dummy variable comparing data with respect to values at time zero (pre-treatment).

A value of $P<0 \cdot 05$ was considered to be statistically significant.

\section{Results}

As results in the three placebo groups did not differ, they were grouped together. Pre-treatment hormone values were similar between the three groups of Maca treatment (Maca 1, Maca 2 and Maca 3). As the results obtained from the Maca $1(1.5 \mathrm{~g})$ and the Maca $3(1.5 \mathrm{~g})$ groups were not different, these data were grouped. Therefore, groups of Maca will be referred to as Maca $1.5 \mathrm{~g}$ (Maca 1+Maca 3) or Maca 3.0 g (Maca 2).

Two-way analysis of variance showed that serum basal levels of $\mathrm{LH}, \mathrm{FSH}$, and PRL were similar between placebo and the two Maca groups before treatment $(P$, not significant (NS)) and at all times of treatment $(P, N S)$ (Fig. 1). Data on serum levels of 17-OHP, testosterone, and estradiol are shown in Fig. 2. Two-way ANOVA showed that testosterone and estradiol levels were similar in the placebo, Maca $1.5 \mathrm{~g}$ and Maca $3.0 \mathrm{~g}$ groups $(P, \mathrm{NS})$. No changes were observed over time $(P, \mathrm{NS})$. At 2 weeks of treatment, higher levels of 17-hydroxyprogesterone were observed in the group treated with $3.0 \mathrm{~g}$ Maca compared with those observed in the groups treated with placebo $(P<0.001)$ or Maca $1.5 \mathrm{~g}(P<0 \cdot 001)$. In the other groups of treatment and times of treatment there were no differences $(P, \mathrm{NS})$. After percentage transformation, the differences in serum levels of 17-OHP at two weeks of treatment disappeared $(P, \mathrm{NS})$.

Table 1 shows data on two-way analysis of variance obtained after logarithmic transformation of serum hormone levels. No differences between treatments and between times of treatment were observed for serum $\log \mathrm{FSH}$, serum $\log \mathrm{LH}$ and serum $\log$ PRL levels. At 2 weeks of treatment, serum levels of $\log 17-\mathrm{OHP}$ were higher in the group treated with Maca $3.0 \mathrm{~g}$ than in the placebo group or in the Maca $1.5 \mathrm{~g}$ group. At other times no differences were observed. Serum log testosterone and serum log estradiol levels were similar between treatments and between times of treatment $(P, \mathrm{NS})$.
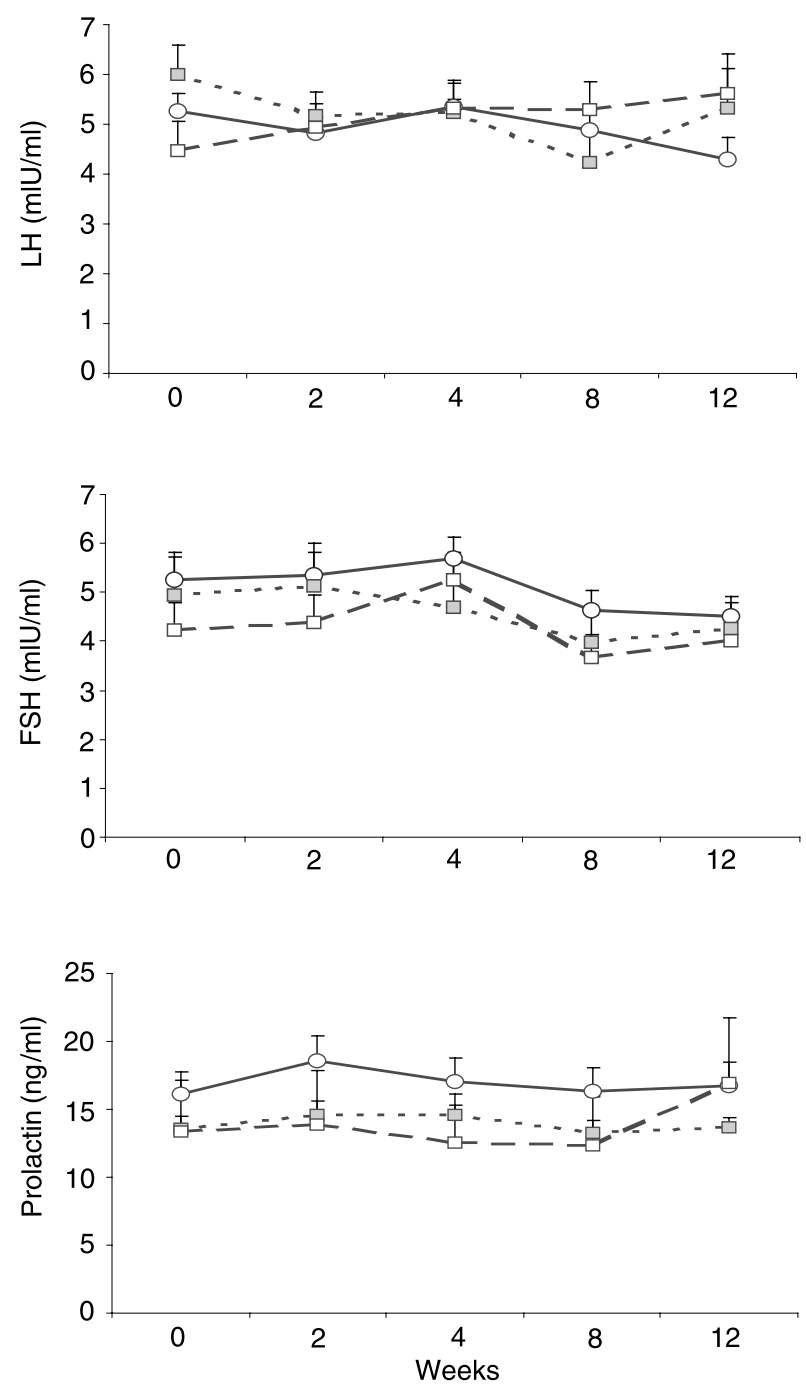

Figure 1 Serum levels of luteinizing hormone (LH), folliclestimulating hormone $(\mathrm{FSH})$, and prolactin in healthy men treated with Maca ( $1.5 \mathrm{~g}$ (open circles) or $3.0 \mathrm{~g}$ (shaded boxes)) or placebo (open boxes) over 12 weeks. Data are means \pm S.E.M.

Multiple regression analysis showed that serum testosterone levels were not affected by either treatment $(P, \mathrm{NS})$ or time of treatment $(P, \mathrm{NS})$. Serum 17-OHP $(P<0 \cdot 001)$ and serum estradiol $(P<0 \cdot 01)$ levels were directly related to serum testosterone levels (Table 2).

\section{Discussion}

The use of herbs is very common in developing countries, particularly in rural settings. However, during the last decade an increase in the use of plants has been observed in metropolitan areas of developed countries (Harnack et al. 2001). 

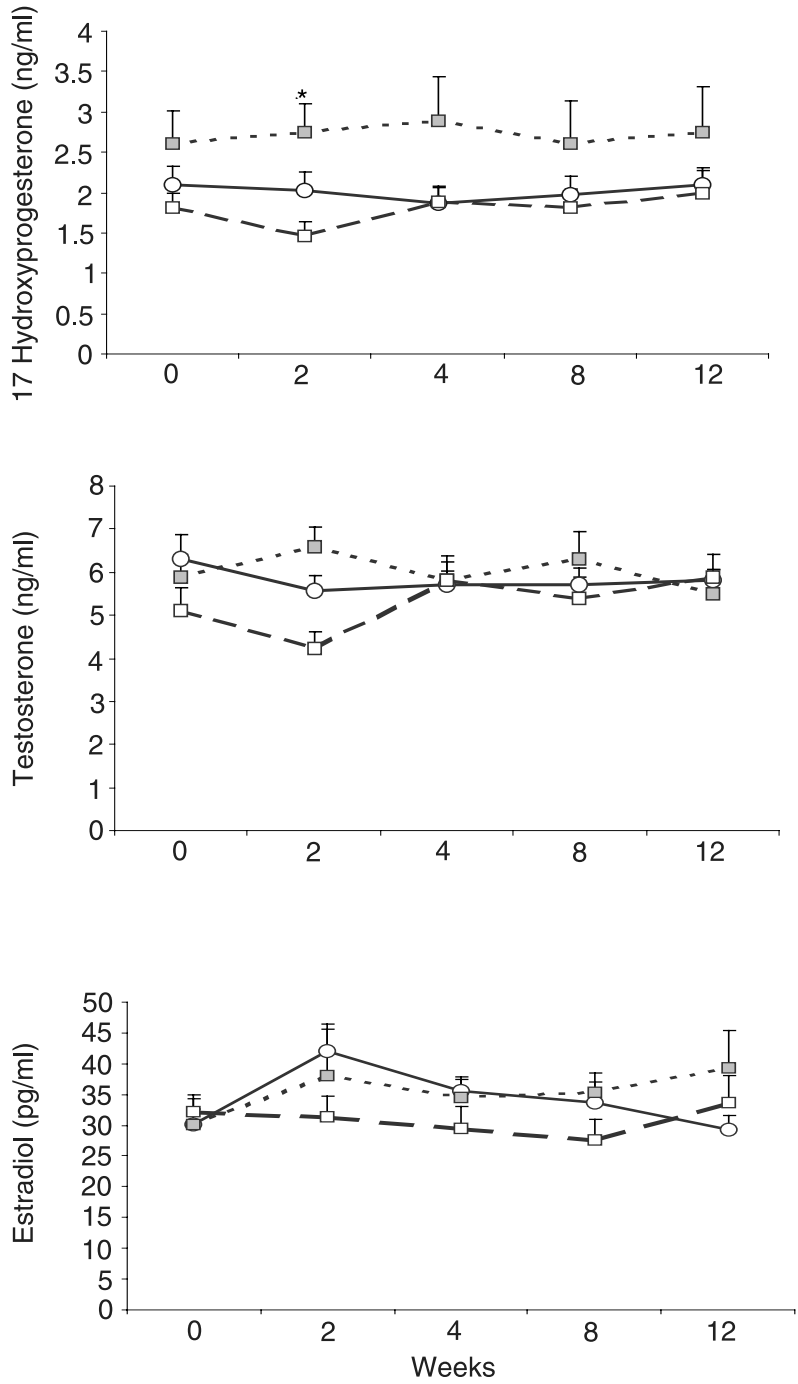

Figure 2 Serum levels of 17-hydroxyprogesterone, testosterone and estradiol in healthy men treated with Maca ( $1.5 \mathrm{~g}$ (open circles) or $3.0 \mathrm{~g}$ (shaded boxes)) or placebo (open boxes) over 12 weeks. Data are means \pm S.E.M. ${ }^{*} P<0 \cdot 001$ with respect to Maca $1.5 \mathrm{~g}$ and placebo.

Sexual difficulties are extremely prevalent among both men and women. They are associated with a number of biological, medical, and psychological risk factors and increase markedly with aging (Leiblum 1999). There have been a number of important approaches to restore sexual function. Plants are extensively used to relieve sexual dysfunction. Ginseng, for example, is an essential constituent in traditional Chinese medicine (Kim et al. 1976) and at least 6 million Americans use the root of this slow-growing perennial (Nocerino et al. 2000).

Another root, known as Maca (Lepidium meyenii), has traditionally been used by Peruvian inhabitants living at high altitudes as a nutrient, an energizer and for aphro-

Table 1 Two way analysis of variance to assess independent effect of treatment with Maca $(1.5 \mathrm{~g}$ or $3.0 \mathrm{~g})$ or placebo over a period of 12 weeks on serum log luteinizing hormone, log follicle-stimulating hormone, log prolactin, log 17-alpha hydroxyprogesterone, log testosterone, and log 17-beta estradiol levels in apparently healthy men. Data refers to two-way analysis of variance performed for each hormone

Source

Hormone (logarithm)

Luteinizing hormone

Follicle-stimulating hormone

Prolactin

17-Alpha

hydroxyprogesterone

Testosterone

Estradiol

\begin{tabular}{|c|c|c|}
\hline Source & $F$ value & $\boldsymbol{P}$ \\
\hline Treatment & $0 \cdot 59$ & NS \\
\hline Time of treatment & $1 \cdot 39$ & NS \\
\hline Treatment & $2 \cdot 86$ & NS \\
\hline Time of treatment & $1 \cdot 83$ & NS \\
\hline Treatment & $1 \cdot 34$ & NS \\
\hline Time of treatment & $1 \cdot 38$ & NS \\
\hline Treatment & $7 \cdot 02$ & $0 \cdot 001$ \\
\hline Time of treatment & $0 \cdot 40$ & NS \\
\hline Treatment & $2 \cdot 37$ & NS \\
\hline Time of treatment & $0 \cdot 49$ & NS \\
\hline Treatment & $0 \cdot 91$ & NS \\
\hline Time of treatment & $1 \cdot 37$ & NS \\
\hline
\end{tabular}

Serum hormones were transformed to logarithm. NS, not significant.

Table 2 Multiple regression analysis to demonstrate an effect of Maca on serum testosterone levels over 12 weeks of treatment

\begin{tabular}{|c|c|c|c|}
\hline & $\begin{array}{l}\text { Coefficient of } \\
\text { regression } \\
\pm \text { standard error }\end{array}$ & $P$ & $\begin{array}{l}\text { 95\% Confidence } \\
\text { interval }\end{array}$ \\
\hline 17-OHP & $0 \cdot 29 \pm 0 \cdot 08$ & 0.001 & $0 \cdot 130.46$ \\
\hline Estradiol & $0 \cdot 02 \pm 0 \cdot 01$ & $0 \cdot 01$ & $0.004 \quad 0.03$ \\
\hline Maca $1.5 \mathrm{~g}$ & $0 \cdot 37 \pm 0 \cdot 27$ & NS & $-0.17 \quad 0.92$ \\
\hline Maca $3.0 \mathrm{~g}$ & $0 \cdot 36 \pm 0 \cdot 33$ & NS & -0.301 .02 \\
\hline Treatment 2 weeks & $-0 \cdot 59 \pm 0 \cdot 34$ & NS & -1.270 .09 \\
\hline Treatment 4 weeks & $-0 \cdot 28 \pm 0 \cdot 34$ & NS & -0.960 .39 \\
\hline Treatment 8 weeks & $-0.21 \pm 0.35$ & NS & $-0.90 \quad 0.48$ \\
\hline Treatment 12 weeks & $-0 \cdot 30 \pm 0 \cdot 35$ & NS & -0.990 .40 \\
\hline Constant & $4 \cdot 50 \pm 0 \cdot 39$ & 0.0001 & $3 \cdot 72 \quad 5 \cdot 29$ \\
\hline
\end{tabular}

Maca treatment $(1.5$ or $3.0 \mathrm{~g})$ was compared with placebo (variable dummy). Treatment 2, 4, 8 and 12 weeks were related to values at 0 weeks (variable dummy).

NS, not significant.

disiac and/or fertility-enhancing properties. Maca grows in the central Andes of Peru at altitudes between 4000 and $4500 \mathrm{~m}$ and it has been proved to be effective in improving sexual desire in men (Córdova et al. 2001), and sexual behavior in male rats and mice (Zheng et al. 2000, Cicero et al. 2001, 2002).

In a 12-week, double-blind, placebo-controlled, randomized, parallel trial, Maca at doses of $1.5 \mathrm{~g}$ or $3.0 \mathrm{~g}$ improved sexual desire in healthy men. Data obtained at 4 , 8 and 12 weeks of treatment demonstrated that Maca improved sexual desire as compared with placebo at 8 and 12 weeks of treatment (Córdova et al. 2001). 
At the present time it is difficult to ascertain if the effect of Maca on sexual desire is due to a direct effect of an active product of Maca or to an indirect effect. Certainly, sexual desire may be affected directly by increasing serum testosterone levels or by having a testosterone-like effect, or indirectly by affecting behavioral depression, stress (Kumar et al. 2001), anxiety (Rowland et al. 1987) and sedation (Ratnasooriya \& Dharmasiri 2000). Improvement of depression by selective serotonin reuptake inhibitors in depressed patients has been associated with improvement in sexual function (Ekselitus \& von Knorring 2001, Michelson et al. 2001).

It is well known that low serum testosterone levels are related to low sexual desire, and that an increase in serum testosterone levels results in resumption of sexual activity (Jannini et al. 1999). However, in normal men the differences in circulating testosterone concentration within the normal range do not account for differences in sexual activity and interest (Brown et al. 1978). Furthermore, an increase in testosterone levels over normal values may have undesirable effects such as the possibility that testosterone may be a promoter of prostate cancer (Nelson \& White 2002). Our results demonstrated that Maca did not increase serum reproductive hormone levels including serum testosterone levels.

Data in the literature suggest that testosterone should not be used to improve sexual desire in men with normal serum testosterone levels. Treatment with Maca may be an interesting alternative, since it improves sexual desire (Córdova et al. 2001) as reported previously, without affecting serum testosterone levels as has been demonstrated in the present study.

It is also possible that Maca may contain testosteronelike compounds. However, data previously reported have demonstrated that seminal vesicle weight, a target organ for androgens, was similar in rats treated with Maca and in those of controls (Gonzales et al. 2001a).

Another hormone related to sexual function is prolactin. When present in serum in normal concentrations this hormone may facilitate sexual response in men (Rowland et al. 1987). However, hyperprolactinemia is related to low libido (Schwartz et al. 1982) and full restoration of libido is contingent on reduction of circulating prolactin to normal or near-normal levels (Schwartz et al. 1982). In the present study, serum prolactin levels were unaffected during treatment with 1.5 or $3.0 \mathrm{~g}$ Maca.

Serum LH levels were also unaffected in men treated with placebo and in those treated with $1.5 \mathrm{~g}$ or $3.0 \mathrm{~g}$ Maca. The lack of change in the group treated with Maca is in accordance with the absence of change in serum testosterone levels.

Serum FSH levels were not affected in men treated with Maca or placebo. The fact that serum FSH remained unaffected over the period of treatment may suggest that the improvement in spermatogenesis observed previously in men (Gonzales et al. 2001b) is due to an effect at the testicular level. However, this needs to be demonstrated.

Serum 17-OHP levels remained mainly unchanged during treatment with placebo or Maca. As 17-OHP is a testosterone precursor, our data suggest that testosterone production was not affected by treatment with Maca. Testosterone is metabolized to estradiol. At this time, data suggest that using Maca at doses of 1.5 or $3.0 \mathrm{~g}$, enough to improve sexual desire, do not affect the production and/or catabolism of testosterone.

It is possible that Maca may contain phyto-estrogens as occurs in other plants. Phyto-estrogens may have estrogenic or anti-estrogenic activities (Kuiper et al. 1998). Recently, remarkable progress has been made in our understanding of the role of sex steroids in human male physiology. A possible role of estrogens in both human male fertility and sexuality has also been suggested by recent studies (Rochira et al. 2001). A well-established effect of estrogens has been provided by recent studies on male rodents, which show impaired sexual behavior and fertility as a consequence of estrogen defect (O'Donnell et al. 2001). The emerging physiological role of estrogens in male fertility suggests that estrogenic substances should be considered 'male hormones' (O'Donnell et al. 2001). At this time it is difficult to conclude that treatment with Maca contributes a male hormone in the form of phytoestrogens which would lead to improvement in sexual function. Further studies will be required to clarify the mechanism of action of Maca on male sexuality and fertility.

Maca, when used appropriately, appears to be relatively safe. It is considered a food supplement, not a drug, and it is available in many countries including the United States. The present study was designed in healthy men due to the fact that Maca is used mainly by this kind of person. It was important to know if serum testosterone levels were increased with the doses of 1.5 and $3.0 \mathrm{~g}$ Maca which are commonly taken by users. After 12 weeks of Maca administration at any of the dosages used no side effects different to placebo administration were observed.

Further studies are needed to determine in what kind of subjects with sexual dysfunction is the administration of Maca in tablet form helpful, and to determine the effect of Maca on hormone levels in patients with sexual dysfunction. Such effects could be different to those seen in normal subjects, but this needs to be proved. In conclusion, treatment with tablets of Maca at 1.5 to $3.0 \mathrm{~g}$ per day for 12 weeks in healthy men did not affect serum reproductive hormone levels including serum testosterone levels.

\section{Acknowledgements}

The authors thank Manuel Gasco and Julio Rubio for their help in this work. This study was supported by Laboratories Hersil. 


\section{References}

Arver S, Dobs AS, Meikle AW, Allen RP, Sanders SW \& Mazer NA 1996 Improvement of sexual function in testosterone deficient men treated for 1 year with a permeation enhanced testosterone transdermal system. Journal of Urology 155 1604-1608.

Brown WA, Monti PM \& Corriveau DP 1978 Serum testosterone and sexual activity and interest in men. Archives of Sexual Behavior 7 97-103.

Cicero AF, Bandieri E \& Arletti R 2001 Lepidium meyenii Walp. improves sexual behaviour in male rats independently from its action on spontaneous locomotor activity. Journal of Ethnopharmacology 75 225-229.

Cicero AF, Piacente S, Plaza A, Sala E, Arletti R \& Pizza C 2002 Hexanic Maca extract improves rat sexual performance more effectively than methanolic and chloroformic Maca extracts. Andrologia 34 177-179.

Córdova A, Vega K, Villena A \& Gonzales GF 2001 Efecto del Lepidium meyenii (Maca) una planta alto-andina sobre el estado de ánimo y el deseo sexual en varones aparentemente normales. Reprodução e Climatério (Suppl) 16 96-97.

Ekselitus L \& von Knorring L 2001 Effect on sexual function of long-term treatment with selective serotonin reuptake inhibitors in depressed patients treated in primary care. Journal of Clinical Psychopharmacology 21 154-160.

Gonzales GF, Ruiz A, Gonzales C, Villegas L \& Córdova A 2001a Effect of Lepidium meyenii (Maca) roots on spermatogenesis of male rats. Asian Journal of Andrology 3 231-233.

Gonzales GF, Córdova A, Gonzales C, Chung A, Vega K \& Villena A $2001 \mathrm{~b}$ Improved sperm count after administration of Lepidium meyenii (Maca) in adult men. Asian Journal of Andrology 3 301-304.

Haren MT, Morley JE, Chapman IM, O'Loughlin PD \& Wittert GA 2002 Defining 'relative' androgen deficiency in aging men: how should testosterone be measured and what are the relationships between androgen levels and physical, sexual and emotional health? Climateric 5 15-25.

Harnack LJ, Rydell SA \& Stang J 2001 Prevalence of use of herbal products by adults in the Minneapolis/St Paul, Minn, metropolitan area. Mayo Clinic Proceedings 76 688-694.

Jannini EA, Screponi E, Carosa E, Pepe M, Lo Giudice F, Trimarchi F \& Benvenga Si 1999 Lack of sexual activity from erectile dysfunction with a reversible reduction in serum testosterone. International Journal of Andrology 22 385-392.

Kim C, Choi H, Kim CC, Kim JK \& Kim MS 1976 Influence of ginseng on mating behavior of male rats. American Journal of Clinical Medicine 4 163-168.

Kuiper GG, Lemmen JG, Carlsson B, Corton JC, Safe SH, van der Saag PT et al. 1998 Interaction of estrogenic chemicals and phytoestrogens with estrogen receptor $\beta$. Endocrinology 139 $4252-4263$.
Kumar V, Singh PN \& Bhattacharya SK 2001 Anti-stress activity of Indian Hypericum perforatum L. Indian Journal of Experimental Biology 39 344-349.

Laumann EO, Paik A \& Rosen RC 1999 Sexual dysfunction in the United States: prevalence and predictors. Journal of the American Medical Association 281 537-544.

Leiblum SR 1999 Sexual problems and dysfunction: epidemiology, classification, and risk factors. Journal of Gender-Specific Medicine 2 $41-45$.

Matsumoto AM 1994 Hormonal therapy of male hypogonadism. Endocrinology and Metabolism Clinics of North America 23 857-875.

Michelson D, Schmidt M, Lee J \& Tepner R 2001 Changes in sexual function during acute and six-month fluoxetine therapy: a prospective assessment. Journal of Sex and Marital Therapy 27 289-302.

Nelson KA \& Witte JS 2002 Androgen receptor CAG repeats and prostate cancer. American Journal of Epidemiology 155 883-890.

Nocerino E, Amato M \& Izzo AA 2000 The aphrodisiac and adaptogenic properties of ginseng. Fitoterapia 71 S1-S5.

Obregon LD 1998 Maca. pp 19-63. Lima: Instituto de Fitoterapia Americana.

O'Donnell L, Robertson KM, Jones ME \& Simpson ER 2001 Estrogen and spermatogenesis. Endocrine Reviews 22 289-318.

Perras B, Smolnik R, Fehm HL \& Born J 2001 Signs of sexual behaviour are not increased after subchronic treatment with LHRH in young men. Psychoneuroendocrinology 26 1-15.

Ratnasooriya WD \& Dharmasiri MG 2000 Effects of Terminalia catappa seeds on sexual behaviour and fertility of male rats. Asian Journal of Andrology 2 213-219.

Rochira V, Balestrieri A, Madeo B, Baraldi E, Faustini-Fustini M, Granata AR \& Carani C 2001 Congenital estrogen deficiency: in search of the estrogen role in human male reproduction. Molecular and Cellular Endocrinology 178 107-115.

Rowland DL, Heiman JR, Gladue BA, Hatch JP, Doering CH \& Weiler SJ 1987 Endocrine, psychological and genital response to sexual arousal in men. Psychoneuroendocrinology 12 149-158.

Schwartz MF, Bauman JE \& Masters WH 1982 Hyperprolactinemia and sexual disorders in men. Biological Psychiatry 17 861-876.

Seidman SN 2000 Hormonal aspects of sexual dysfunction: the therapeutic use of exogenous androgens in men and women. Current Psychiatry Reports 2 215-222.

Zheng BL, He K, Kim CH, Rogers L, Shao Y, Huang ZY, Lu Y, Yan SJ, Qien LC \& Zheng QY 2000 Effect of a lipidic extract from Lepidium meyenii on sexual behavior in mice and rats. Urology 55 598-602.

Received in final form 23 August 2002 Accepted 16 September 2002 